\title{
Retraction Note to: Green city economic efficiency based on cloud computing and machine learning
}

\author{
Zhang Jin ${ }^{1}$
}

Published online: 23 November 2021

(c) Saudi Society for Geosciences 2021

Retraction Note to: Arabian Journal of Geosciences (2021) 14: 1007 https://doi.org/10.1007/s12517-021-07204-1

The Editor-in-Chief and the Publisher have retracted this article because the content of this article is nonsensical. The peer review process was not carried out in accordance with the Publisher's peer review policy. The author disagrees with this retraction.

Zhang Jin

newzhangjin@126.com

1 Beijing BlueWing Technology Co., Ltd., Beijing, China 